\title{
Transport of Two Metal Oxide Nanoparticles in Saturated Granular Porous Media: Role of Water Chemistry and Particle Coating
}

\author{
Revised and resubmitted to: \\ Water Research \\ November 14, 2011
}

\begin{abstract}
ADAMO RICCARDO PETOSA, SPENCER JOHN BRENNAN, FARAZ RAJPUT, and NATHALIE TUFENKJI
\end{abstract}

Department of Chemical Engineering, McGill University,
3610 University St., Montreal, Quebec, Canada H3A 2B2

\footnotetext{
*Corresponding Author: Nathalie Tufenkji

Phone: (514) 398-2999; Fax: (514) 398-6678; E-mail: nathalie.tufenkji@mcgill.ca
} 


\begin{abstract}
The growing use of nanosized titanium dioxide $\left(n \mathrm{TiO}_{2}\right)$ and zinc oxide $(n \mathrm{ZnO})$ in a large number of commercial products raises concerns regarding their release and subsequent mobility in natural aquatic environments. Laboratory-scale sand-packed column experiments were conducted with bare and polymer-coated $n \mathrm{TiO}_{2}$ and $n \mathrm{ZnO}$ to improve our understanding of the mobility of these nanoparticles in natural or engineered water saturated granular systems. The nanoparticles are characterized over a range of environmentally relevant water chemistries using multiple complimentary techniques: dynamic light scattering, nanoparticle tracking analysis, transmission electron microscopy, and scanning electron microscopy. Overall, bare (uncoated) nanoparticles exhibit high retention within the water saturated granular matrix at solution ionic strengths (IS) as low as $0.1 \mathrm{mM} \mathrm{NaNO}_{3}$ for bare $n \mathrm{TiO}_{2}$ and $0.01 \mathrm{mM} \mathrm{NaNO}_{3}$ for bare $n \mathrm{ZnO}$. Bare $n \mathrm{TiO}_{2}$ and $n \mathrm{ZnO}$ also display dynamic (time-dependent) deposition behaviors under selected conditions. In contrast, the polymer-coated nanoparticles are much less likely to aggregate and exhibit significant transport potential at IS as high as $100 \mathrm{mM} \mathrm{NaNO}_{3}$ or $3 \mathrm{mM} \mathrm{CaCl}_{2}$. These findings illustrate the importance of considering the extent and type of surface modification when evaluating metal oxide contamination potential in granular aquatic environments.
\end{abstract}

Keywords: titanium dioxide, zinc oxide, nanoparticle, transport, nanoparticle tracking analysis, transmission electron microscopy 


\section{Introduction}

The nanotechnology industry is expected to reach a market value of $\$ 1$ trillion by 2015 (Robichaud et al. 2005). According to the US National Nanotechnology Initiative, a substance can be classified as a nanomaterial (NM) if its constituent particles, or nanoparticles (NPs), possess one or more dimensions between 1 and $100 \mathrm{~nm}$ in size (Englert 2007, Robichaud et al. 2005). With the number of NM-containing industrial products growing, the toxicity of their nanosized components has been brought to question, with the scientific community and public expressing their concerns (Maynard et al. 2006, Suzuki et al. 2007). Environmental discharge can occur as a result of NM manufacturing, consumption and disposal (Mueller and Nowack 2008, Nowack and Bucheli 2007, Wiesner and Bottero 2007) and NM release into aquatic systems can result in heightened human and environmental exposure to potentially harmful particles.

Nanosized titanium dioxide $\left(n \mathrm{TiO}_{2}\right)$ and zinc oxide $(n \mathrm{ZnO})$ are known for their ability to absorb UV radiation, and are included in cosmetic and dermatological products (Dufour et al. 2006, Englert 2007, Mueller and Nowack 2008, Sayes et al. 2006). $n \mathrm{TiO}_{2}$ is also sought for its photovoltaic and photocatalytic properties (Tseng and Lin 2003) and is an ingredient in paints, coatings, and building materials (Aitken et al. 2006). Moreover, $n \mathrm{TiO}_{2}$ is a promising candidate for the remediation of contaminated subsurface environments as a high specific surface area enables it to adsorb heavy metals and it has been found to effectively remove arsenic, uranium, lead and technetium (Choy et al. 2008, Pena et al. 2005). $n \mathrm{ZnO}$, another versatile inorganic NP, is utilized in electronics, optics, photonics and pigment applications such as coatings and paints (Adams et al. 2006, Lin and Xing 2008, Wang 2004). Dual semiconducting and piezoelectric properties make 
$n \mathrm{ZnO}$ a valuable material in optoelectronic and photovoltaic devices, lasers, transducers and sensors (Wang 2004, Zhou et al. 2006).

Toxicological studies are gradually shedding light on the potential organismal health threats posed by $n \mathrm{TiO}_{2}$ and $n \mathrm{ZnO}$ exposure. Both in vitro and in vivo toxicity studies have indicated that these particles could be harmful to humans (Huang et al. 2010, Moos et al. 2010, Schanen et al. 2009, Sharma et al. 2009), rodents (Duan et al. 2010, Hu et al. 2010, Ma et al. 2010, Warheit et al. 2007), fish (Bai et al. 2010, Federici et al. 2007, Hao et al. 2009), bacteria (Fang et al. 2010, Ge et al. 2011, Reddy et al. 2007, Sinha et al. 2011) and other organisms (Mortimer et al. 2010, Roh et al. 2010, Valant et al. 2009). Because of their significant commercial relevance and potential toxicity, the environmental fate of $n \mathrm{TiO}_{2}$ and $n \mathrm{ZnO}$ is of growing interest. Once released into aquatic environments, the potential ecotoxicological and public health risks associated with metal oxide nanoparticles will be influenced by their fate and transport within these systems. Hence, a number of researchers have examined the aggregation and deposition behavior of various NPs in granular aqueous systems in an effort to better understand their contamination potential in the natural subsurface (groundwater) or engineered (deep-bed) water filtration systems (Petosa et al. 2010).

Limited studies have examined $n \mathrm{TiO}_{2}$ aggregation and deposition in granular porous media, with conflicting findings (Petosa et al. 2010). For example, Choy et al. (Choy et al. 2008) investigated the transport of $n \mathrm{TiO}_{2}$ suspensions through sand-packed columns at various flow velocities. Under all conditions examined, high particle retention was observed. Retention was unaffected by flow velocity and a majority of the particles were retained in the first few centimeters of sand. These researchers suggested that distinct transport processes may occur at different column 
depths (Choy et al. 2008). In contrast, Guzman et al. (Guzman et al. 2006) found that although $n \mathrm{TiO}_{2}$ aggregated over a large range of solution chemistries, aggregates were not retained even under favorable deposition conditions (i.e., oppositely charged NP and collector surfaces). In contrast, Fatisson et al. (Fatisson et al. 2009) showed that deposition of $n \mathrm{TiO}_{2}$ did readily occur under conditions favorable for deposition onto a model sand (silica) surface. Indeed, these researchers found that $n \mathrm{TiO}_{2}$ deposition rates onto silica were greatest under conditions deemed favorable for deposition; namely, low IS and $\mathrm{pH}$ below the NP point of zero charge $\left(\mathrm{pH}_{\mathrm{pzc}}\right)$. Nano- $\mathrm{TiO}_{2}$ deposition rates onto the model sand surface were much lower when particles and collector surfaces carried a like charge at a $\mathrm{pH}$ of 9 (Fatisson et al. 2009).

Very few studies have examined $n \mathrm{ZnO}$ transport and deposition in aquatic systems and none have investigated transport in water-saturated sand media. Ben-Moshe et al. examined the transport behavior of $n \mathrm{TiO}_{2}$ and $n \mathrm{ZnO}$ particles in columns packed with glass beads. These researchers demonstrated that while increasing solution IS resulted in heightened metal oxide NP deposition, the presence of dissolved humic acid enhanced NP mobility. At neutral $\mathrm{pH}, n \mathrm{TiO}_{2}$ exhibited far greater mobility than $n \mathrm{ZnO}$ (62\% elution versus $1.4 \%$ elution in $10 \mathrm{mM} \mathrm{NaCl}$, respectively). In the presence of humic acid, $n \mathrm{ZnO}$ elution from the column packed with glass beads was found to range between 68 to $74 \%$ (depending on the flow rate), while $98 \%$ of the $n \mathrm{TiO}_{2}$ eluted (regardless of flow rate) (Ben-Moshe et al. 2010). Jiang et al. examined the deposition kinetics of $n \mathrm{ZnO}$ onto bare and humic acid coated silica (Jiang et al. 2010). Overall, the results of their study were in qualitative agreement with the Derjaguin-Landau-Verwey-Overbeek (DLVO) theory of colloidal stability (Derjaguin and Landau 1941, Verwey and Overbeek 1948); namely, greater $n \mathrm{ZnO}$ deposition onto 
bare silica was observed with increasing solution IS when particle and collector surfaces were negatively charged. Moreover, while the presence of divalent salt resulted in heightened deposition, the presence of humic acid on the silica surface generally hindered deposition.

The purpose of this study is to evaluate the transport potential of bare and polymer-coated $n \mathrm{TiO}_{2}$ and $n \mathrm{ZnO}$ particles in granular aquatic environments. Well-controlled laboratory experiments were conducted to assess the transport behavior of selected bare and polymer-coated metal oxide NPs over a range of solution IS in the presence of monovalent and divalent salts. The hydrodynamic diameters of the suspended NPs were also evaluated using dynamic light scattering (DLS) and nanoparticle tracking analysis (NTA). The flow rate and sandy collectors employed in this study may be representative of those which are encountered in riverbank and slow sand filtration (Ray et al. 2003), thus providing insight into the effectiveness of these two treatment approaches in retaining suspended metal oxide NPs.

\section{Materials and methods}

\subsection{Nanoparticle suspension preparation}

Bare $n \mathrm{TiO}_{2}(5 \mathrm{~nm}$ by transmission electron microscopy (TEM)) and $n \mathrm{ZnO}(20 \mathrm{~nm}$ by TEM) (Nanostructured \& Amorphous Materials, Inc.) and polymer-coated $n \mathrm{TiO}_{2}(3-4 \mathrm{~nm}$ by TEM) and $n \mathrm{ZnO}$ (3-9 nm by TEM) powders (Vive $\mathrm{Nano}^{\mathrm{TM}}$ ) were used to prepare NP suspensions. The crystalline form of the NPs was anatase for the $n \mathrm{TiO}_{2}$ and amorphous for $n \mathrm{ZnO}$. Details on product purity are provided in the Supporting Information. The Vive Nano ${ }^{\mathrm{TM}}$ particles are coated with partially crosslinked polyacrylic acid. Bare and polymer-coated particle stock suspensions were 
prepared using (with minor alterations) the Protocol for Nanoparticle Dispersion provided by the PROSPEcT Global Nanomaterials Safety partnership (http://www.nanotechiaprospect.org/managed_assets/files/prospect_dispersion_protocol.pdf). Briefly, $0.1 \mathrm{~g}$ of NP powder was weighed into a $250 \mathrm{~mL}$ beaker containing a few drops of deionized (DI) water. The NPs were then mixed with a stainless steel spatula, and the beaker filled to $200 \mathrm{~mL}$ with DI water, stirred, and then ultrasonicated for $60 \mathrm{sec}(90 \%$ amplitude, 4A, 50/60 Hz, Hielscher UP200S Ultrasonic Processor), yielding a $0.5 \mathrm{~g} / \mathrm{L}$ stock suspension. All stock suspensions were kept for a maximum of two days at $4^{\circ} \mathrm{C}$.

$n \mathrm{TiO}_{2}$ and $n \mathrm{ZnO}$ suspensions for experimentation $(30$ and $100 \mathrm{mg} / \mathrm{L}$ concentrations, respectively) were prepared by diluting the stock suspensions in sodium nitrate $\left(\mathrm{NaNO}_{3}\right.$, SigmaAldrich) with IS ranging from $0.1-1000 \mathrm{mM}$ for $n \mathrm{TiO}_{2}$ and 0.01 to $1000 \mathrm{mM}$ for $n \mathrm{ZnO}$. Polymer-coated nanoparticle suspensions were also examined in solutions of $1-10 \mathrm{mM} \mathrm{CaCl}_{2}$ (Sigma-Aldrich). The $\mathrm{pH}$ of $n \mathrm{TiO}_{2}$ suspensions was maintained at 7 using $1 \mathrm{mM}$ MOPS (3-(Nmorpholino)propanesulfonic acid, Sigma-Aldrich). Theoretical predictions of $\mathrm{ZnO}$ dissolution (based on the chemical equilibrium model Visual MINTEQ) indicate that virtually all of the $n \mathrm{ZnO}$ would dissolve at or below $\mathrm{pH} 7$. For this reason, experiments conducted with $n \mathrm{ZnO}$ were conducted at $\mathrm{pH} 8$. NP suspensions were stored for $\sim 20 \mathrm{hrs}$ (in the dark) prior to conducting characterization and transport experiments. Immediately prior to each experiment, suspension flasks were gently inverted manually and then analyzed. 


\subsection{Nanoparticle imaging}

Field emission gun scanning electron microscopy (FEG-SEM) (Hitachi S-4700) was employed to characterize $n \mathrm{ZnO}$ aggregates. Prior to imaging, $n \mathrm{TiO}_{2}$ suspensions were left to dry on glass slides and $\mathrm{Au} / \mathrm{Pd}$ coated using a sputter coater. SEM slides (glass coverslips) were prepared as follows. First, coverslips were soaked in $100 \mathrm{~mL}$ of $70 \% \mathrm{HNO}_{3}$ in a glass beaker at room temperature for 10 min with occasional swirling. The coverslips were rinsed with tap water for $30 \mathrm{~min}$, then rinsed with DI water and left to soak in DI water for $10 \mathrm{~min}$ (with occasional swirling). This rinsing procedure was repeated three times. Finally, the coverslips were soaked in $100 \mathrm{~mL}$ methanol (Fisher) for an additional $10 \mathrm{~min}$, air-dried in a fume hood overnight and then stored in a clean glass Petri dish. To

prepare SEM samples, coverslips were placed into a 24-well polystyrene plate, rinsed three times with $1 \mathrm{~mL}$ DI water and then once with NP suspension to avoid dilution. Next, $1 \mathrm{~mL}$ of NP suspension was added to each well. After $4 \mathrm{~h}$, the remaining liquid was carefully removed using a pipette and the glass slides were left to dry overnight. SEM analysis was performed the following day, subsequent to $\mathrm{Au} / \mathrm{Pd}$ coating.

TEM images of bare $n \mathrm{TiO}_{2}$ and $n \mathrm{ZnO}$ powders were obtained by dusting particles onto a carbon/formvar-coated copper grid and using a model JEM-2100F field emission electron microscope set at $200 \mathrm{kV}$ (JEOL Canada Inc., St Hubert, QC, Canada).

\subsection{Nanoparticle size and electrokinetic characterization}

NP hydrodynamic diameters (number mean) were determined by dynamic light scattering (DLS) using a Malvern Zetasizer Nano. Hydrodynamic diameters were also determined by nanoparticle 
tracking analysis (NTA), using a Nanosight LM10 (with an LM14 viewing unit) NTA system (Nanosight, Wiltshire, UK). At least three independent replicate samples were analyzed using DLS and NTA. NP electrophoretic mobilities (EPMs) were determined by laser Doppler velocimetry (ZetaSizer Nano ZS, Malvern). All EPM measurements were performed at $25^{\circ} \mathrm{C}$, with an applied electrical field $(E)$ of $4.9 \pm 0.1 \mathrm{~V} / \mathrm{m}$.

\subsection{Nanoparticle transport and deposition studies}

Nanoparticle transport studies were performed using glass columns (16 mm inner diameter, GE Life Sciences) packed with high purity fine quartz sand $\left(-50+70\right.$ mesh size,$d_{50}=256 \mu \mathrm{m}$, Sigma-

Aldrich). Prior to use, sand was acid-washed as previously described (Litton and Olson 1993, Pelley 2008) to remove impurities.

Before all transport experiments, the required mass of sand was soaked in electrolyte for a minimum of 16 hrs. To ensure uniform packing, sand was wet packed into glass columns using gentle vibration yielding a packed-bed porosity of 0.37 . To further condition the collector surfaces, at least ten pore volumes (PVs) of electrolyte (at the desired $\mathrm{pH}$ and IS) were pumped through the packed column prior to injecting the NP suspension. A UV-visible spectrophotometer $(1 \mathrm{~cm}$ flowthrough cell, Hewlett-Packard 8453) was used to obtain real-time influent $\left(C_{0}\right)$ and effluent $(C)$ particle concentration measurements. The presence of a polymer coating altered the wavelengths at which NPs could be monitored. While bare $n \mathrm{TiO}_{2}$ and $n \mathrm{ZnO}$ were observed at $\lambda=550$ and $369 \mathrm{~nm}$ respectively, polymer-coated $\mathrm{NPs}$ were observed at $\lambda=250\left(n \mathrm{TiO}_{2}\right)$ and $300 \mathrm{~nm}(n \mathrm{ZnO})$. At least three PVs of the NP suspension were injected into the column to allow observation of initial particle breakthrough and any time-dependent changes in NP elution behavior. The flow rate for all 
deposition experiments was $0.5 \mathrm{~mL} / \mathrm{min}$ (equivalent to an approach or Darcy velocity of $3.6 \mathrm{~m} /$ day). Deposition data was highly reproducible and each breakthrough curve reported is the average of 3 column experiments.

To confirm the results obtained by UV-visible spectrophotometry, column influent and effluent NP concentrations were also obtained using inductively coupled plasma atomic emission spectroscopy (ICP-AES) (Thermo Jarrell Ash, Trace Scan). Column effluent samples ( $0.5 \mathrm{~mL})$ were collected in polypropylene tubes following UV-visible analysis, digested with $100 \mu \mathrm{L}$ of $70 \% \mathrm{HNO}_{3}$ and then stored overnight at $4^{\circ} \mathrm{C}$. Prior to ICP-AES analysis, $400 \mu \mathrm{L}$ of each sample was diluted in $1600 \mu \mathrm{L}$ of the corresponding $\mathrm{NaNO}_{3}$ electrolyte. Representative ICP-AES data is provided (Supplementary Material, Fig. S1). Additionally, the relative stability of the NP suspensions was confirmed by sedimentation tests (UV-visible spectrophotometry) and DLS measurements (ZetaSizer Nano) (data not shown). In this study, suspensions are referred to as stable when sedimentation tests and DLS measurements indicated that sample absorbance and aggregate size, respectively, did not fluctuate over the time course of a column experiment.

\section{$2.5 \mathrm{nZnO}$ Dissolution}

It is known that $n \mathrm{ZnO}$ is prone to dissolution (Domingos et al. 2009a, Franklin et al. 2007). The extent of $n \mathrm{ZnO}$ dissolution was verified experimentally using a dialysis technique as described by Franklin et al. (Franklin et al. 2007) with some minor alterations. Briefly, 1000 Da MWCO Spectra/Por 7 dialysis membranes were filled with DI water and placed into $5 \mathrm{~L}$ beakers containing $100 \mathrm{mg} / \mathrm{L} n \mathrm{ZnO}$ suspensions $\left(\mathrm{pH} 8,1 \mathrm{mM} \mathrm{NaNO}\right.$ ). The concentration of $\mathrm{Zn}^{2+}$ ion present in 100 
$\mathrm{mg} / \mathrm{L} \mathrm{ZnO}$ particle suspensions ( $\mathrm{pH} 8 \pm 0.2$ ) was determined over a time span of $26 \mathrm{~h}$ (Fig. S2), which is equivalent to the duration of a complete transport experiment including suspension preparation and equilibration periods. Prior to sampling, the membrane surface was wiped carefully with a Kimwipe, and samples were removed from within the dialysis membranes using a syringe (mounted with a BD 18G1 needle). Next, $4 \mathrm{~mL}$ of sample was placed into a polypropylene tube containing $1 \mathrm{~mL} \mathrm{HNO}_{3}$, and the samples were digested for $1 \mathrm{hr}$ at $90^{\circ} \mathrm{C}$, stored overnight at room temperature and finally analyzed by ICP-AES. Two samples originating from different dialysis bags were analyzed for each time point and the suspension $\mathrm{pH}$ remained $8 \pm 0.1$ throughout the dialysis experiments. As only a negligible fraction $(-1-2 \%)$ of the $n \mathrm{ZnO}$ was found to dissolve over the time course of an experiment (Supplementary Material, Fig. S2), it can be assumed that dissolution does not affect particle deposition or aggregation under the conditions examined here. $n \mathrm{ZnO}$ dissolution at $\mathrm{pH} 8$ was also determined theoretically using the chemical equilibrium model Visual MINTEQ ver. 3.0, and the concentration of dissolved $\mathrm{Zn}^{2+}$ predicted to be $\sim 1.5 \mathrm{mg} / \mathrm{L}$.

\section{Results and discussion}

\subsection{Nanoparticle properties}

\subsubsection{Size of suspended $n \mathrm{TiO}_{2}$ and $n \mathrm{ZnO}$ particles}

Particle size is one of the key factors influencing NP transport behavior in granular aqueous systems (Petosa et al. 2010). In aquatic environments, the actual size of many NMs is typically far greater than reported nominal sizes due to stable aggregate formation (Dhawan et al. 2006, Lecoanet et al. 2004, Lecoanet and Wiesner 2004). In this study, several complimentary particle sizing techniques 
were used to characterize the $n \mathrm{TiO}_{2}$ and $n \mathrm{ZnO}$ suspensions and original powders. Although all NP suspensions used in this study were prepared from powders having small nominal sizes $(3-5 \mathrm{~nm}$ and 3-20 nm for $n \mathrm{TiO}_{2}$ and $n \mathrm{ZnO}$, respectively), SEM imaging clearly demonstrates polydispersity within the suspensions, with micron-sized and nano-sized aggregates present (Fig. 1).

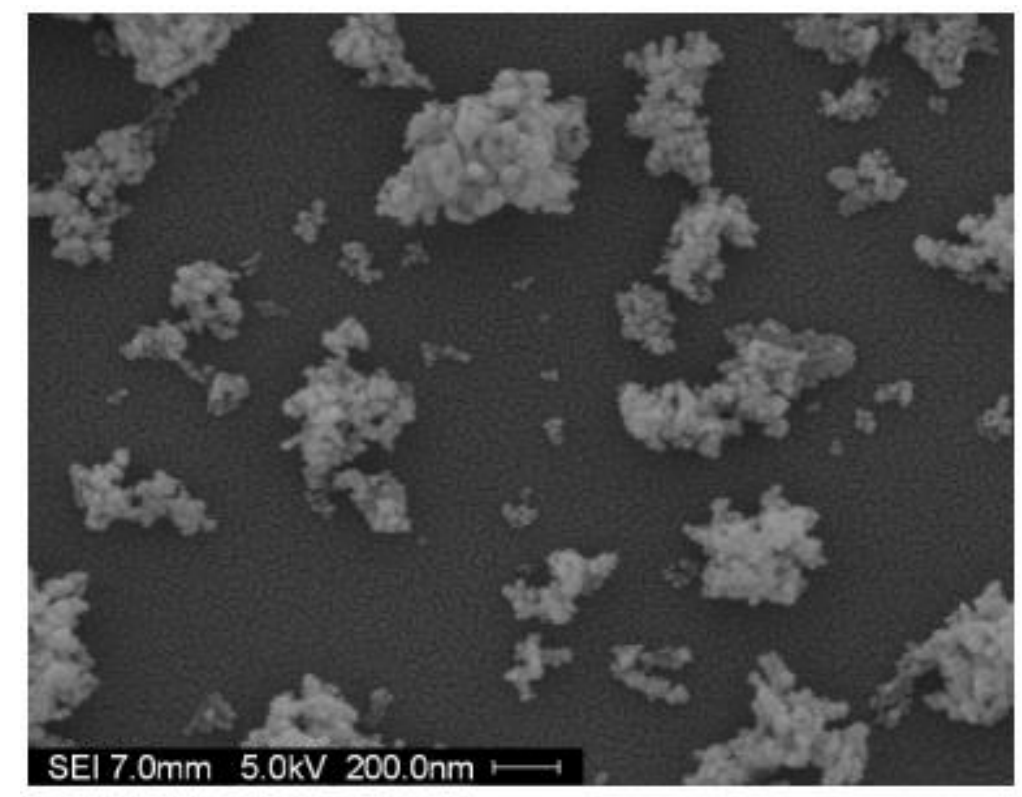

FIGURE 1. SEM image of bare $n \mathrm{ZnO}\left(\mathrm{pH} 8,0.1 \mathrm{mM} \mathrm{NaNO}_{3}\right)$.

TEM images of the bare NP powders demonstrate that many particles aggregated even prior to suspension preparation (Fig. 2). Although this is expected because of the strong van der Waals force in the solid state, it is interesting that the two different metal oxides exhibit different types of aggregation. TEM images of the bare $n \mathrm{TiO}_{2}$ powder show the formation of densely packed aggregates (Fig. 2b), whereas images of the bare $n \mathrm{ZnO}$ powder reveal the presence of less densely packed aggregates, with clearly defined individual particles within the aggregates (Fig. 2d). TEM images of $n \mathrm{ZnO}$ also confirm the $20 \mathrm{~nm}$ nominal size. 

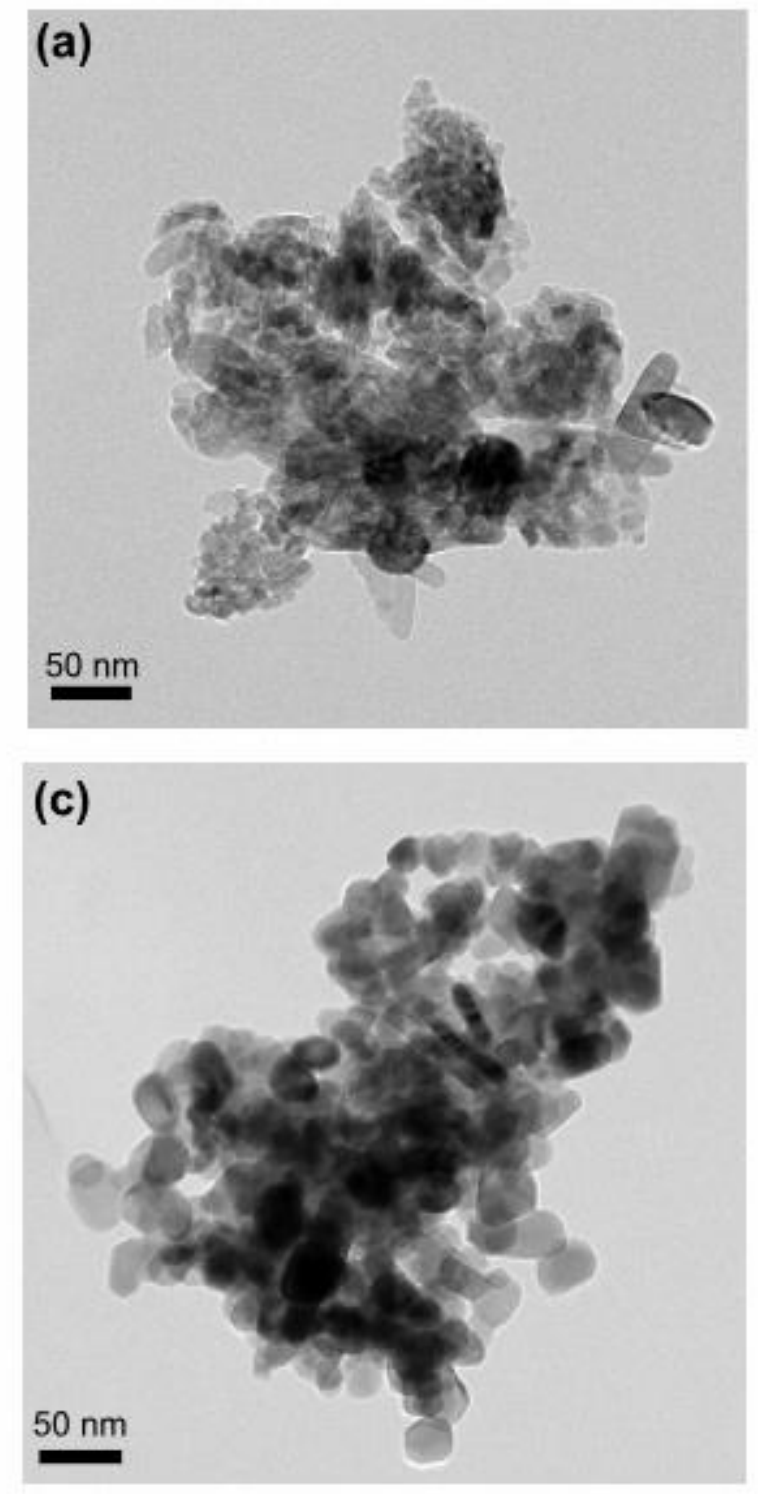
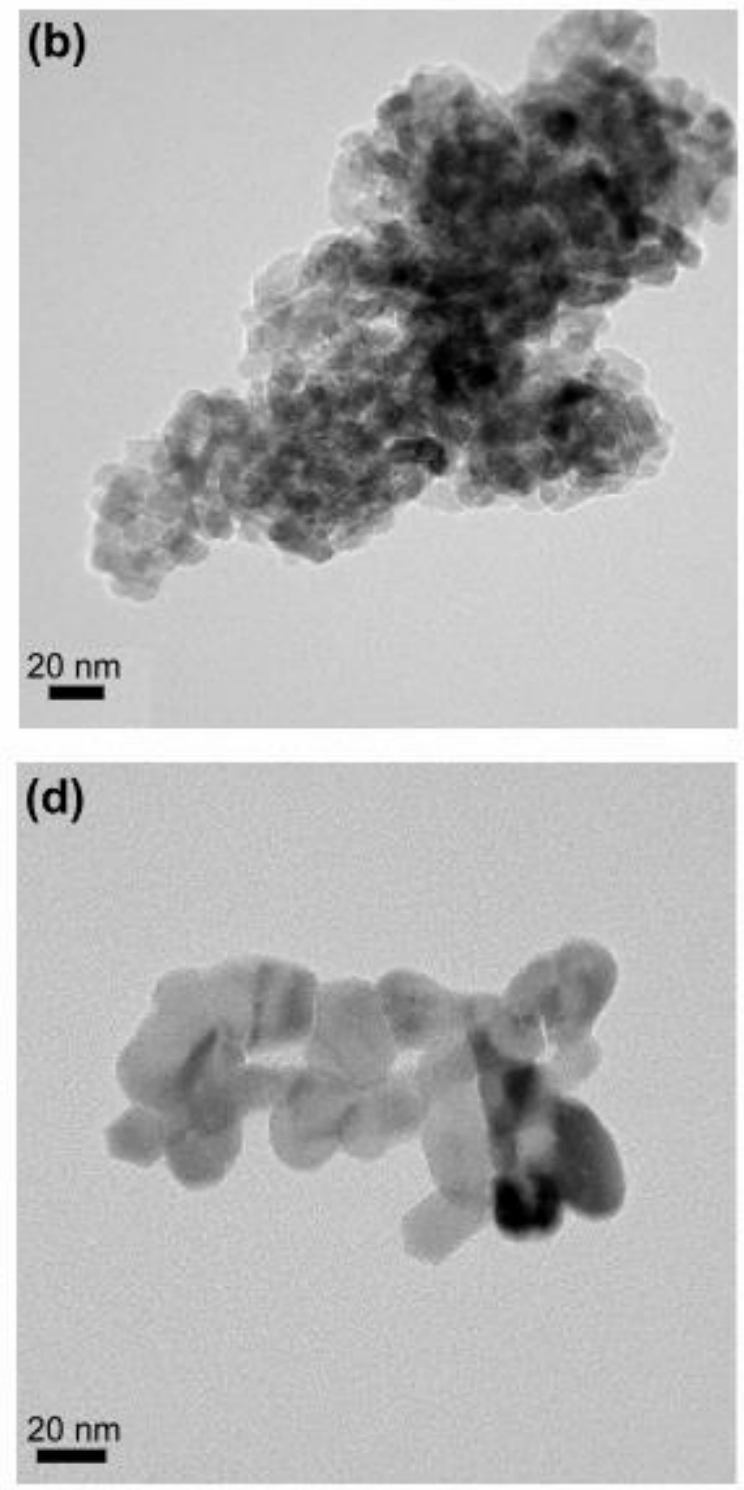

FIGURE 2. TEM images of $(\mathrm{a}, \mathrm{b})$ bare $n \mathrm{TiO}_{2}$ and (c, d) bare $n \mathrm{ZnO}$ powders.

In addition to the SEM and TEM imaging, DLS particle sizing also signals the presence of large aggregates $(>500 \mathrm{~nm})$ in the suspensions of bare NPs at higher IS (Table 1). Bare $n \mathrm{TiO}_{2}$ particle sizes obtained by DLS generally reveal an increase in particle (or aggregate) size with increasing solution IS. Specifically, for the bare $n \mathrm{TiO}_{2}$, the particle size increases from $\sim 128 \mathrm{~nm}$ at $0.1 \mathrm{mM} \mathrm{NaNO}_{3}$ to $-934 \mathrm{~nm}$ at $100 \mathrm{mM} \mathrm{NaNO}_{3}$ (based on DLS). As expected, the NTA 
measurements do not capture the larger sized particles present at high IS (Carr et al. 2008). Bare $n \mathrm{ZnO}$ is examined over a smaller range of IS due to the decreased stability of this material; namely, the bare $n \mathrm{ZnO}$ particle size exceeds $1 \mu \mathrm{m}$ at an IS of $10 \mathrm{mM} \mathrm{NaNO}_{3}$ (Table 1). DLS and NTA measurements suggest that bare $n \mathrm{ZnO}$ size increases with heightened salt concentrations, as expected due to electrical double layer (EDL) compression and subsequent aggregation. The bare $n \mathrm{TiO}_{2}$ and $n \mathrm{ZnO}$ particles were not studied in divalent salt solutions as preliminary measurements revealed these suspensions to be highly unstable, even at very low solution IS.

Table 1 also lists values of the polydispersity index (PDI) from the DLS measurements. The PDI is an indicator of the polydispersity of the suspension where a value $<0.1$ reflects a relatively narrow monomodal distribution, a value between 0.1 and 0.5 suggests a broader distribution, and a value exceeding 0.5 indicates that the particle size distribution is very broad and the cumulants analysis approach may not be valid. Interestingly, PDI values are on the order of 0.5 or greater for suspensions of bare $n \mathrm{TiO}_{2}$ but lower (on the order of 0.3 ) for the bare $n \mathrm{ZnO}$ even though the latter exhibits a lower critical coagulation concentration (CCC) as estimated from the sizing data. This suggests that the bare $n \mathrm{TiO}_{2}$ forms aggregates of varying size whereas the size distribution of $n \mathrm{ZnO}$ aggregates is narrower. 


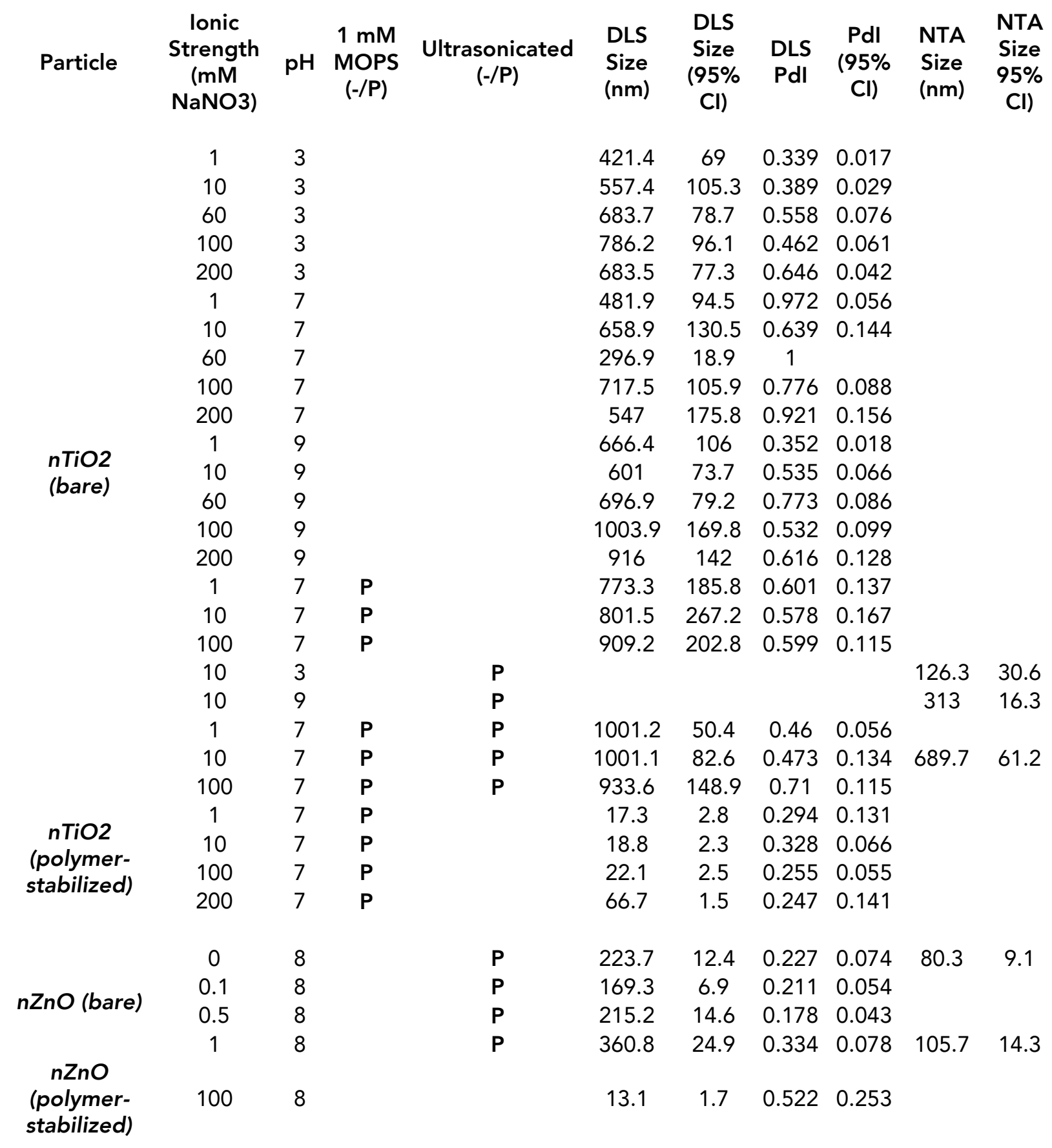


The polymer-coated nanoparticle suspensions are significantly more stable over a wider range of solution chemistries (Table 1$)$. Polymer-coated $n \mathrm{TiO}_{2}$ exhibits little or no aggregation $\left(d_{\mathrm{DLS}}-20\right.$ $\mathrm{nm})$ and generally low polydispersity $(\mathrm{PDI} \leq 0.3)$ from 1 to $100 \mathrm{mM} \mathrm{NaNO}_{3}$. The particle size $\left(d_{\mathrm{DLS}}-200 \mathrm{~nm}\right)$ and PDI $(0.85)$ increase significantly at the highest IS examined $(1000 \mathrm{mM}$ $\mathrm{NaNO}_{3}$ ), yet, the aggregates are still much smaller at this high IS than those formed with the bare $n \mathrm{TiO}_{2}$ at $100 \mathrm{mM} \mathrm{NaNO}_{3}$. A similar trend is noted for polymer-coated $n \mathrm{TiO}_{2}$ suspended in $\mathrm{CaCl}_{2}$, whereby the mean DLS particle size and the PDI greatly increased at $8 \mathrm{mM}$ IS. The hydrodynamic size (by DLS) and EPM of the polymer-coated $n \mathrm{TiO}_{2}$ could not be evaluated at IS higher than 8 $\mathrm{mM} \mathrm{CaCl} 2$ due to the significant instability of prepared suspensions. Yet, overall, the polymer coating of the $n \mathrm{TiO}_{2}$ renders this material more stable as evidenced by the lower particle sizes measured in the divalent salt solution versus those evaluated for the bare particle in a monovalent salt solution. Polymer-coated $n \mathrm{ZnO}$ is also generally stable in suspension as evidenced by the sizing measurements: for instance, $d_{\mathrm{DLS}}-13 \mathrm{~nm}\left(\right.$ at $100 \mathrm{mM} \mathrm{NaNO}_{3}$ ) for the polymer-coated particle, whereas the size of the bare NP exceeds $1300 \mathrm{~nm}$ at $10 \mathrm{mM}$ IS. Measurements were also conducted with polymer-coated $n \mathrm{ZnO}$ in the presence of the divalent salt. Although mean DLS particle sizes do not exceed those measured for the bare particle in a monovalent salt of comparable IS, PDI values significantly exceeded 0.5 at higher $\mathrm{CaCl}_{2}$ concentrations. Hence, these DLS measurements at the highest $\left[\mathrm{CaCl}_{2}\right]$ are likely less reliable.

While DLS data is useful for identifying trends in particle size, the hydrodynamic diameters obtained by DLS should be considered as estimates of particle or aggregate size. DLS is best suited for the analysis of NP suspensions exhibiting simple (e.g., monomodal or bimodal) particle size 
distributions (Ryan and Elimelech 1996). Many of the NP suspensions employed in this study were polydisperse (Table 1). Since Rayleigh scattering is proportional to the particle diameter raised to the $6^{\text {th }}$ power, the reported $d_{\mathrm{DLS}}$ are biased by the largest aggregates (Domingos et al. 2009a). Hence, DLS should not be employed as the sole characterization method. Thus, we also used TEM, SEM and NTA to (i) investigate the aggregation state of the particles prior to suspension in background electrolytes, (ii) confirm the presence of nanosized particles within the suspensions and (iii) observe the impact of solution chemistry on aggregate size, respectively.

$n \mathrm{TiO}_{2}$ aggregation has been observed at extreme $\mathrm{pHs}$ (e.g., $\mathrm{pH} 1,2$ ), away from the $\mathrm{pH}_{\mathrm{prc}}$, where all particles carry like charges (Guzman et al. 2006, Pettibone et al. 2008). As the $\mathrm{pH}_{\mathrm{pzc}}$ is approached, interparticle repulsive forces decrease, thus heightening aggregation (Domingos et al. 2009b). Aqueous titania (primarily anatase, with a nominal size between $5-12 \mathrm{~nm}$ ) suspensions have previously been found to be more stable under acidic conditions, with observed aggregate sizes not necessarily symmetric around the $\mathrm{pH}_{\mathrm{pzc}}$ (Guzman et al. 2006). Those particles were synthesized by controlled hydrolysis. In another study utilizing commercially available particles, it has been reported that at $\mathrm{pHs}$ far from the $\mathrm{pH}_{\mathrm{prc}}$, smaller $\left(5 \mathrm{~nm}\right.$ ) primary anatase $n \mathrm{TiO}_{2}$ particles (from Nanostructured and Amorphous Materials, Inc) generated larger aggregates than $32 \mathrm{~nm}$ particles (from Alfa Aesar) (Pettibone et al. 2008). Thus, the small nominal particle sizes employed in the present study potentially increased the extent of aggregation. 


\subsubsection{Electrokinetic characterization of suspended $n \mathrm{TiO}_{2}$ and $n \mathrm{ZnO}$ particles}

NP EPMs were determined to provide an indication of the NP surface charge under different solution conditions and to obtain the $\mathrm{pH}_{\mathrm{pzc}}$. The $\mathrm{pH}_{\mathrm{pzc}}$ for $n \mathrm{TiO}_{2}$ depends on the crystal structure and particle size (Finnegan et al. 2007, Guzman et al. 2006). The average $\mathrm{pH}_{\mathrm{pzc}}$ reported for bulk $\mathrm{TiO}_{2}$ is 5.6, with a value of 5.9 and 5.4 for the anatase and rutile forms, respectively (Kosmulski 2002). Smaller NPs have been found to possess lower $\mathrm{pH}_{\mathrm{pzc}}$ values (e.g., $\mathrm{pH}_{\mathrm{pzc}}$ of 4.8 for $3.6 \mathrm{~nm}$ $n \mathrm{TiO}_{2}$, versus 6.2 for $8.1 \mathrm{~nm}$ particles) (Finnegan et al. 2007, Guzman et al. 2006). Given the reported variations in particle isoelectric points, the $\mathrm{pH}_{\mathrm{pzc}}$ for the bare NPs employed in this study was determined experimentally and found to be 5.6 for $n \mathrm{TiO}_{2}$ and 9.8 for $n \mathrm{ZnO}$ (Supporting Information, Fig. S3).

Table 1 shows that the EPM of the $n \mathrm{TiO}_{2}$ particles is negative over the range of IS examined $\left(0.1-100 \mathrm{mM} \mathrm{NaNO}_{3}\right.$ for the bare NPs and $1-200 \mathrm{mM} \mathrm{NaNO}_{3}$ for the polymer-coated NPs) at pH 7. In the monovalent salt solution, the polymer-coated $n \mathrm{TiO}_{2}$ particles are more negatively charged than the bare NPs at corresponding IS. The polymer-coated NPs also generally exhibit a lower absolute EPM in the divalent salt solution versus the monovalent salt solution at corresponding IS. Finally, we observe a decrease in the absolute EPM with increasing IS (i.e., with increased compression of the EDL) for the bare and the polymer-coated $n \mathrm{TiO}_{2}$ particles. Using 5 nm bare $n \mathrm{TiO}_{2}$ particles (anatase, Nanostructured and Amorphous Materials, Inc) suspended in $\mathrm{NaNO}_{3}$, Domingos et al. (Domingos et al. 2009b) also observed a decrease in EPM with increasing IS, with an EPM of approximately $1 \mu \mathrm{mcm} / \mathrm{Vsec}$ observed at $100 \mathrm{mM}$ IS, $\mathrm{pH} 7$ (comparable to the findings presented here). Their study also reports that adding fulvic acid to the NP suspensions 
produced significantly more negative EPMs, with charge reversal observed at $\mathrm{pH}$ values below the $\mathrm{pH}_{\mathrm{pzc}}$. Likewise, Joo et al. (Joo et al. 2009) reported that carboxymethylcellulose encapsulation of $n \mathrm{TiO}_{2}$ (anatase, $10 \mathrm{~nm}$ nominal size) increased the absolute particle surface charge and resulted in surface charge reversal at lower $\mathrm{pH}$ values (below $\mathrm{pH}$ 5). The increase in surface charge subsequently resulted in increased interparticle repulsion and heightened mobility in sand-packed columns.

The EPM of $n \mathrm{ZnO}$ was also determined as a function of IS at $\mathrm{pH} 8$ (Table 1). Generally, $n \mathrm{ZnO}$ NPs have been found to possess positive surface potentials at or below $\mathrm{pH} 8$ (Ben-Moshe et al. 2010, Zhang et al. 2009, Zhou and Keller 2010). Here, the EPM of bare $n Z n O$ ranges between 1.95 and $0.555 \mu \mathrm{mcm} / \mathrm{Vsec}$ when the IS is varied from 0.1 to $10 \mathrm{mM} \mathrm{NaNO}_{3}$ at $\mathrm{pH} 8$ (Table 1 ). The EPM of the bare NPs generally becomes less positive with increasing concentration of $\mathrm{NaNO}_{3}$. Chowdhury et al. (Chowdhury et al. 2010) found that increasing the IS from 0.1 to $100 \mathrm{mM} \mathrm{KCl}$ caused $n \mathrm{ZnO}(10 \mathrm{~nm}$ nominal size, Meliorum Technologies) EPM to decrease from 1.81 to 0.70 $\mathrm{m}^{2} \mathrm{~V}^{-1} \mathrm{~s}^{-1}$ (pH 7.9). Nonetheless, increasing the IS from 0.1 to $10 \mathrm{mM}$ did not result in any significant decrease in EPM. Rather, an obvious change was only observed between 10 to $100 \mathrm{mM}$ IS. They attributed the relatively constant EPM observed below $10 \mathrm{mM} \mathrm{KCl}$ to the dissolution of $n \mathrm{ZnO}$ particles and the shielding effects of the $\mathrm{Zn}^{2+}$ ions present. In contrast, Jiang et al. (Jiang et al. 2010) found the $\zeta$-potential of bare $n \mathrm{ZnO} N \mathrm{NP}$ to be negative at $\mathrm{pH} 7.8(1-150 \mathrm{mM} \mathrm{NaCl}$ and $0.05-5 \mathrm{mM} \mathrm{CaCl}_{2}$ ) and reported that this discrepancy was specific to particles obtained from one particular manufacturer. Whereas the bare $n \mathrm{ZnO}$ particles used here exhibit a positive surface charge at $\mathrm{pH} 8$, polymer-coated $n \mathrm{ZnO}$ exhibits a negative EPM over the range of solution conditions examined. Similarly, Zhang et al. (Zhang et al. 2009) observed charge reversal of $n \mathrm{ZnO}$ 
NPs in the presence of natural organic matter. Hence, in the presence of polymer coatings or natural organic matter, NP surface charge reversal may occur that can subsequently affect NP transport and deposition. Reproducible measurements of the EPM of polymer-coated $n \mathrm{ZnO}$ particles could not be obtained at the higher IS conditions, hence, these are not reported in Table 1. EPM measurements conducted at lower concentrations of $\mathrm{CaCl}_{2}$ (from $1-10 \mathrm{mM}$ ) show that the EPM of these polymer-coated particles becomes less negative with increasing IS.

\subsection{Deposition studies}

\subsubsection{Transport of bare and polymer-coated $n T i \mathrm{O}_{2}$ particles in sand-packed columns}

Laboratory columns packed with clean sand were used to study the transport and deposition behavior of the metal oxide NPs over a wide range of solution chemistries. Representative breakthrough curves for bare and polymer-coated $n \mathrm{TiO}_{2}$ particles are shown in Fig. 3. Error bars have been included on this figure to demonstrate the reproducibility of the transport experiments. To quantitatively compare NP deposition behavior at the various solution conditions investigated, the colloid filtration theory (Yao et al. 1971) was employed to determine NP attachment efficiencies $(\alpha)$ onto the sand surface, as follows:

$$
\alpha=-\frac{2 d_{c}}{3(1-\varepsilon) \eta_{0} L} \ln \left(C / C_{0}\right)
$$

Here, $d_{c}$ is the collector (sand grain) diameter, $\varepsilon$ is the packed bed porosity, $L$ is the packed bed length ( 3 or $10 \mathrm{~cm}$ ), and $C / C_{0}$ is the normalized NP concentration obtained from the experimental breakthrough curves during the initial (clean-bed) phase of nanoparticle elution; specifically, the average value of $C / C_{0}$ is measured between pore volumes 1.8 to 2.0 was used (as per (Tufenkji and 
Elimelech 2004b, 2005)). The value of the single-collector contact efficiency $\left(\eta_{0}\right)$ is determined using the Tufenkji-Elimelech correlation equation (Tufenkji and Elimelech 2004a).

Characterization of nanoparticle suspensions is not straightforward and various measurement techniques present different limitations (Domingos et al. 2009a). For instance, DLS is not well suited to characterize polydisperse suspensions, whereas NTA has an upper size limit on the order of $1 \mu \mathrm{m}$ (Carr et al. 2008). In this study, both techniques are used to obtain estimates of particle hydrodynamic diameters that can be useful in interpreting the nanoparticle transport behavior in sand packed columns. Accordingly, two measures of particle size ( $d_{\mathrm{DLS}}$ and $\left.d_{\mathrm{NTA}}\right)$ were considered in the calculation of $\eta_{0}$, leading to two estimates of the NP attachment efficiency: $\alpha_{\mathrm{DLS}}$ and $\alpha_{\mathrm{NTA}}$ (Table 1). Overall, the two estimates of $\alpha$ are comparable over the range of conditions examined; however, greater differences are noted in the attachment efficiencies of the bare $n \mathrm{ZnO}$ at higher IS. In these cases, the bare nanoparticles form very large aggregates which are not detected by NTA, leading to inaccurate estimates of $\alpha$. For the sake of clarity, only the values of $\alpha_{\text {DLS }}$ are included in Fig. 4 and the related discussion. 

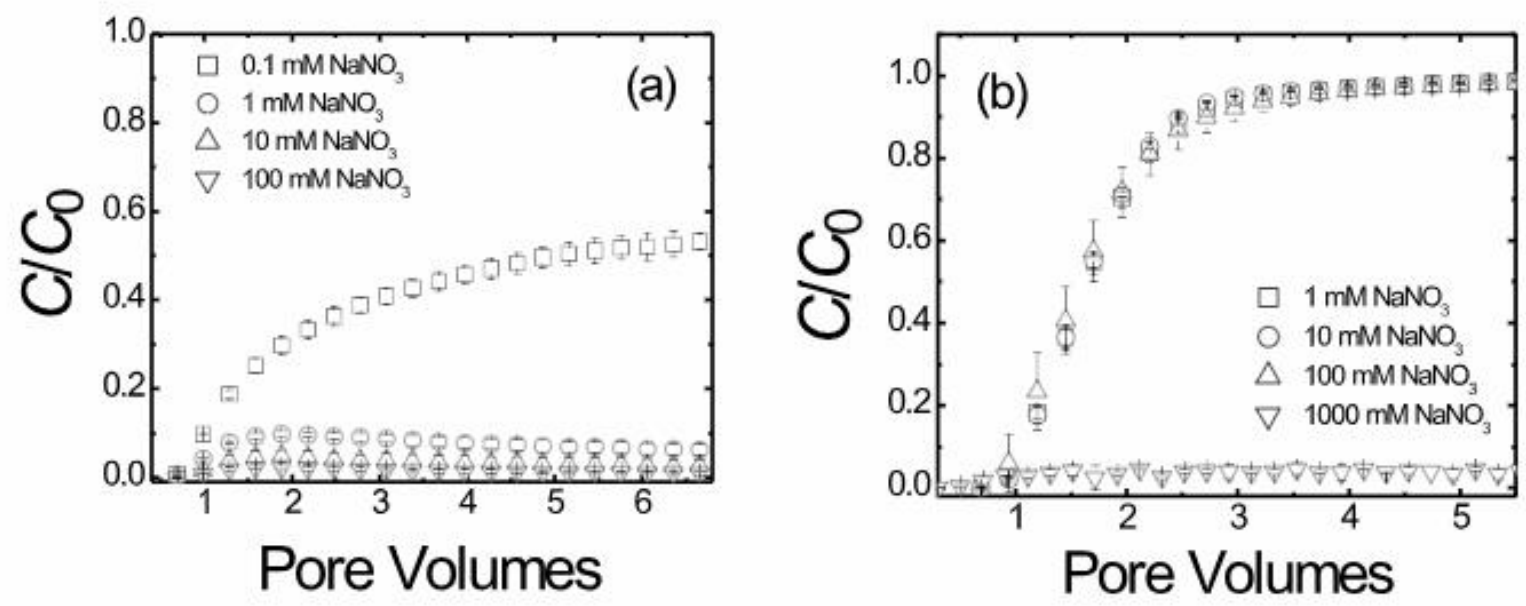

Figure 3. Measured breakthrough curves for (a) bare and (b) polymer-coated $n \mathrm{TiO}_{2}$ particles suspended in $\mathrm{NaNO}_{3}$ at $\mathrm{pH} 7$. 

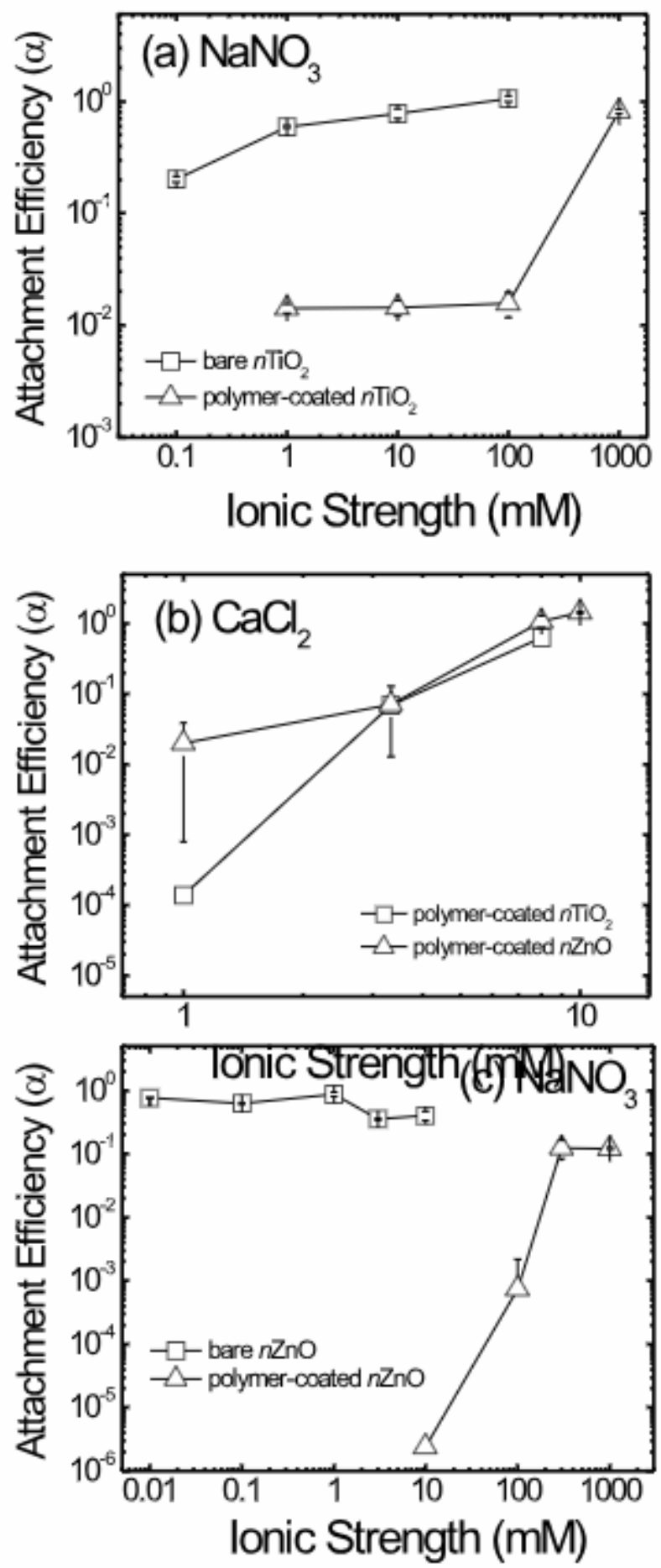

Figure 4. Calculated attachment efficiencies for (a) bare and polymer-coated $n \mathrm{TiO}_{2}$ particles (at pH 7) at different IS of $\mathrm{NaNO}_{3}$; (b) polymer-coated $n \mathrm{TiO}_{2}$ and $n \mathrm{ZnO}$ at different IS of $\mathrm{CaCl}_{2}$; and (c) bare and polymer-coated $n \mathrm{ZnO}$ particles (at $\mathrm{pH} 8$ ) at different IS of $\mathrm{NaNO}_{3}$. 
Fig. 3 shows significant retention of bare $n \mathrm{TiO}_{2}$ over a broad range of concentrations of the monovalent salt (at $\mathrm{pH}$ 7); namely, $\alpha$ varies from 0.2 to $\sim 1$ when the IS is increased from 0.1 to 100 $\mathrm{mM} \mathrm{NaNO}_{3}$ (Fig. 3A and Table 1). However, the transport and deposition behavior of the polymer-coated $n \mathrm{TiO}_{2}$ particle is dramatically different (Fig. 3B). Polymer-coated $n \mathrm{TiO}_{2}$ displays extremely low retention in the sand packed columns, with $C / C_{0}$ approaching 1 at IS ranging from 1 to $200 \mathrm{mM} \mathrm{NaNO}_{3}$ (Fig. 3B). Significant retention of this particle is only observed at a salt concentration of $1 \mathrm{M} \mathrm{NaNO}_{3}$. These results reflect the important stabilizing property of the polymer coating on the Vive $\mathrm{Nano}^{\mathrm{TM}}$ particles at IS between 1 and $200 \mathrm{mM} \mathrm{NaNO}$. A polymer coating can give rise to electrosteric stabilization, which can prevent aggregation and deposition (Elimelech et al. 1995, Franchi and O'Melia 2003). Moreover, the small aggregate sizes of the polymer-coated particles (Table 1) reduce the likelihood of physical straining (Bradford et al. 2003, 2006, Bradford et al. 2002), further enhancing the extent of NP transport. As indicated in section 3.1.1., the size of the polymer-coated $n \mathrm{TiO}_{2}$ particles is considerably smaller (18-67 nm when IS varies from 1-200 $\left.\mathrm{mM} \mathrm{NaNO}_{3}\right)$ than that of the bare $n \mathrm{TiO}_{2}(128-934 \mathrm{~nm}$ when IS varies from 1$100 \mathrm{mM} \mathrm{NaNO})_{3}$.

When physicochemical filtration dominates the extent of NP deposition, the NP attachment efficiency $(\alpha)$ is observed to vary over several orders of magnitude with changing water chemistry (i.e., IS and pH) (Petosa et al. 2010). Fig. 4A shows that $\alpha$ values for the bare $n \mathrm{TiO}_{2}$ are generally high $(\geq 0.2)$ and vary only within one order of magnitude over a broad range of solution IS. This behavior suggests that NP retention onto the sand surface is not solely controlled by a physicochemical mechanism of filtration. The high "apparent" $\alpha$ values evaluated for the bare 
$n \mathrm{TiO}_{2}$ even at very low IS $\left(0.1 \mathrm{mM} \mathrm{NaNO}_{3}\right)$ suggest that physical straining is the governing retention mechanism for this particle. The contribution of physical straining to particle retention is not considered in the development of the classical colloid filtration theory; hence, $\alpha$ values evaluated for a system where straining is a contributing factor are considered here to be "apparent" $\alpha$ values. Because NP transport experiments were conducted in columns packed with fine silica sand, the retention of larger aggregates (such as those formed by the bare $n \mathrm{TiO}_{2}$ ) by physical straining is very likely, leading to particle entrapment within the clogged pores. In contrast, measured $\alpha$ values for the polymer-coated $n \mathrm{TiO}_{2}$ are considerably low from $1-100 \mathrm{mM} \mathrm{NaNO}_{3}$ (on the order of $10^{-2}$ ), but are greater at the higher IS of $1 \mathrm{M}$ (Fig. 4A and Table 1).

In an attempt to determine whether a divalent salt would destabilize the polymer-coated $n \mathrm{TiO}_{2}$, suspensions were prepared in $\mathrm{CaCl}_{2}$ solutions ( $\mathrm{pH}$ ), at IS ranging from 1 to $333 \mathrm{mM}$. At 33.3 and $333 \mathrm{mM} \mathrm{CaCl}_{2}$, the polymer-coated $n \mathrm{TiO}_{2}$ suspensions are highly unstable, resulting in erratic transport behavior; hence, this data is not included in Table 1 or Fig. 5A. In contrast, DLS particle sizes are relatively small at the lower IS of 1 and $3.33 \mathrm{mM} \mathrm{CaCl}_{2}$ (Table 1). Complete particle elution is observed in $1 \mathrm{mM} \mathrm{CaCl}_{2}$ (Fig. 5A), whereas greater retention occurs as the concentration of $\mathrm{CaCl}_{2}$ is increased. In $3.33 \mathrm{mM} \mathrm{CaCl}_{2}$, particle elution decreases with increasing time indicating potential filter ripening whereby deposited particles act as additional collectors (Elimelech et al. 1995, Liu et al. 1995). The extent of particle retention increases considerably with moderate increases in $\mathrm{CaCl}_{2}$ concentration (Table 1 and Fig. 5A); however, the dynamic behavior observed at $3.33 \mathrm{mM} \mathrm{CaCl}_{2}$ is not noted at higher IS. The corresponding attachment efficiencies for 
transport experiments conducted with the polymer-coated $n \mathrm{TiO}_{2}$ suspended in $\mathrm{CaCl}_{2}$ are on the order of $1.4 \times 10^{-4}$ at $1 \mathrm{mM}$ IS and increase to $\sim 0.6$ at $8 \mathrm{mM}$ IS (Table 1 and Fig. $4 \mathrm{~B}$ ). 

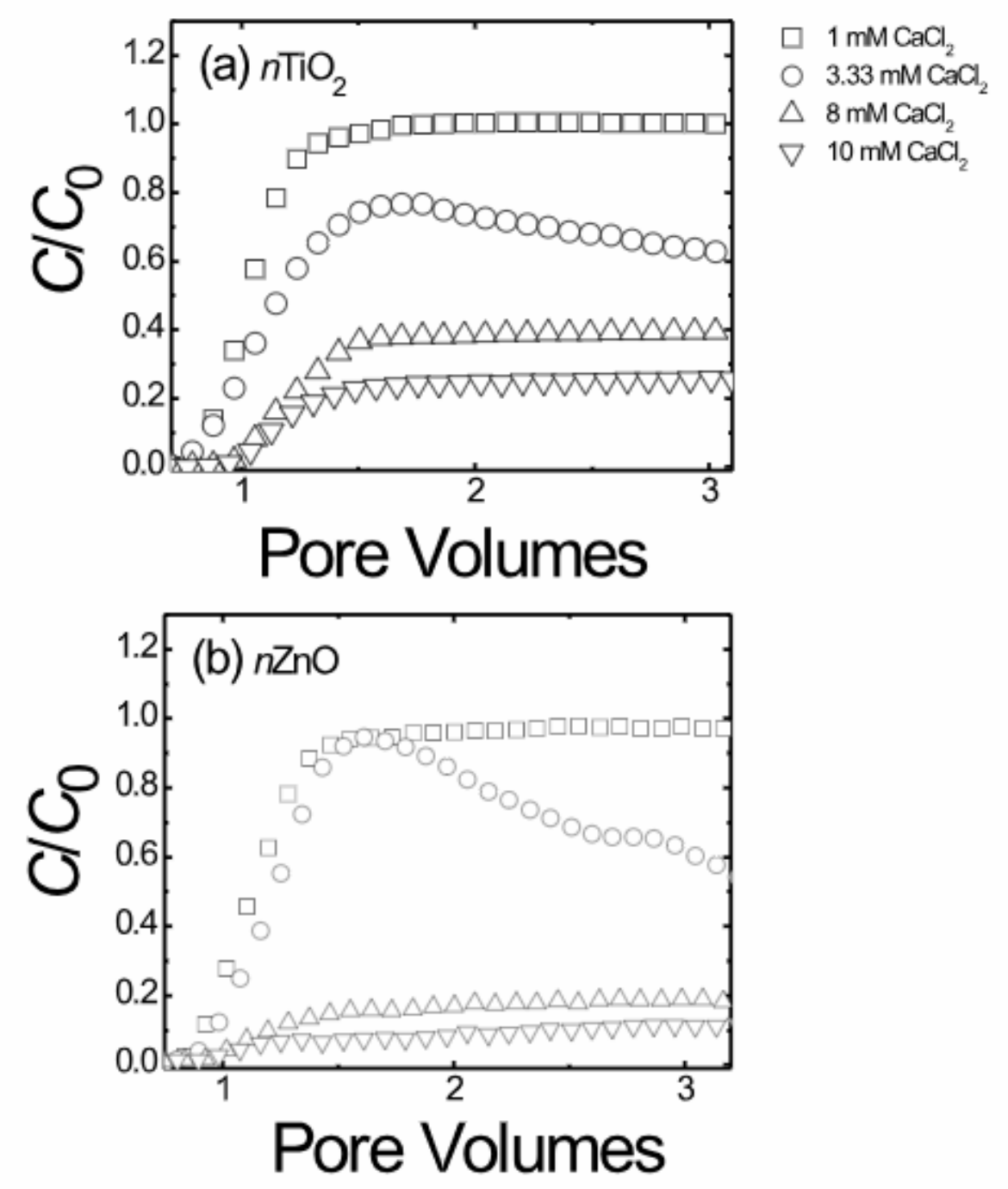

Figure 5. Breakthrough curves for (a) polymer-coated $n \mathrm{TiO}_{2}$ particles (at pH 7) at different IS of $\mathrm{CaCl}_{2}$; and (b) polymercoated $n \mathrm{ZnO}$ particles (at $\mathrm{pH} 8$ ) at different IS of $\mathrm{CaCl}_{2}$.

It is interesting to note that in a study by Ben-Moshe et al. (Ben-Moshe et al. 2010), longer packed columns were used than in the current study $(15 \mathrm{~cm}$ versus $3 \mathrm{~cm})$, yet, these researchers observed significantly greater elution of bare rutile $n \mathrm{TiO}_{2}(<100 \mathrm{~nm}$ nominal size, Aldrich) particles. Specifically, Ben-Moshe et al. (Ben-Moshe et al. 2010) report 62\% elution of particles when suspended in $10 \mathrm{mM} \mathrm{NaCl}$ and $13 \%$ elution in $100 \mathrm{mM} \mathrm{NaCl}$, at $\mathrm{pH} 7$. In contrast, we observed less than $7 \%$ elution of bare anatase $n \mathrm{TiO}_{2}$ in 10 and $100 \mathrm{mM} \mathrm{NaNO}_{3}$ (at $\mathrm{pH}$ 7). In their study, 
however, larger, spherical glass bead collectors $(d=1 \mathrm{~mm})$ were used, while the present study made use of fine $(d=0.26 \mathrm{~mm})$ angular sand. The use of larger, rounder collectors would lessen the impact of physical straining on NP elution (Tufenkji et al. 2004), explaining the heightened elution reported by (Ben-Moshe et al. 2010). Choy et al. (Choy et al. 2008) found that virtually all bare $n \mathrm{TiO}_{2}$ particles injected into sand-packed columns were retained, with 96-100\% retention reported for experiments conducted using $10 \mathrm{mM} \mathrm{NaCl}$. All deposition experiments were performed at $\mathrm{pH}$ 4.5, below the $\mathrm{pH}_{\mathrm{pzc}}$ of the particles. Hence, the particles and collector surfaces were oppositely charged, resulting in favorable deposition conditions. Furthermore, long $30 \mathrm{~cm}$ packed-columns and very fine sand $\left(d_{50}=0.20 \mathrm{~mm}\right)$ were employed, resulting in increased particle retention (Choy et al. 2008). Fatisson et al (Fatisson et al. 2009) also found that bare $n \mathrm{TiO}_{2}$ deposition rates onto silica were greatest under favorable deposition conditions ( $\mathrm{pH} 3$, low IS).

Contrary to Choy et al. and our findings, Guzman et al. (Guzman et al. 2006) found that a large percentage (84\%) of bare $n \mathrm{TiO}_{2}$ particles were transported under favorable deposition conditions (attractive particle-collector interaction energies) at $\mathrm{pH}$ 3. Their study made use of a two-dimensional porous structure (featuring $0.70 \mathrm{~mm}$ spheres with $0.11 \mathrm{~mm}$ spacing) constructed from Pyrex wafers. In contrast to our approach, Guzman et al. employed only those particles that remained in suspension following an equilibration period of 3 months; namely, the most stable fraction of the nanoparticle suspension. Hence, very large aggregates were not included in their study, thus potentially reducing the influence of physical straining and the potential clogging of microchannel pores. Guzman et al. (Guzman et al. 2006) also conducted additional experiments 
where they injected NP aggregates into the porous matrix and found that virtually all aggregates were retained within the porous structure.

A number of researchers have examined the transport of bare $n \mathrm{TiO}_{2}$ particles in water saturated granular matrices; however, only a limited number of studies report the behavior of coated or modified $n \mathrm{TiO}_{2}$ particles in these systems (Joo et al. 2009, Mattigod et al. 2005). Joo et al (Joo et al. 2009) also found that polymer-coated anatase $n \mathrm{TiO}_{2}$ particles were much more mobile than their bare counterparts. The carboxymethyl cellulose (CMC)-coated $n \mathrm{TiO}_{2}$ particles used in their study were more mobile in clean quartz sand $(d=0.29 \mathrm{~mm})$ than in aluminum or iron hydroxide-coated sand. Mattigod et al (Mattigod et al. 2005) found that Cu-ethylenediamine functionalized anatase $n \mathrm{TiO}_{2}$ particles were well dispersed in a $1 \mathrm{~m}$ long column packed with quartz sand. Although other researchers have demonstrated the mobility of coated $n \mathrm{TiO}_{2}$ particles in granular aquatic environments, the range of water chemistries examined in these earlier studies is limited. The experiments presented here with bare and polymer-coated $n \mathrm{TiO}_{2}$ particles (over a broad range of solution IS at $\mathrm{pH} 7$ ) illustrate the important influence of particle surface modifications on NP transport potential in water saturated granular porous matrices.

\subsubsection{Transport of bare and polymer-coated $n Z n O$ particles in sand-packed columns}

The transport and deposition behavior of $n \mathrm{ZnO}$ in sandy granular materials has not previously been reported in the published literature. We conducted a series of experiments using bare and polymercoated $n \mathrm{ZnO}$ over a range of water chemistries to evaluate the influence of a polyelectrolyte coating on NP transport (Figs. 4B, $4 \mathrm{C}$ and 6). The retention of bare $n \mathrm{ZnO}$ is high at all concentrations of 
the monovalent salt tested, with "apparent" attachment efficiencies exceeding 0.35 at all IS (Figs. 4C and 6A). Moreover, inspection of Fig. $6 \mathrm{~A}$ reveals that the deposition rate of bare $n \mathrm{ZnO}$ onto the quartz sand changes as the experiment progresses; at 0.1 and $1 \mathrm{mM} \mathrm{NaNO}_{3}$, the NP deposition rate appears to decrease with time. In contrast, at the other IS examined, the rate of $n \mathrm{ZnO}$ deposition appears to increase with time. Under the experimental conditions examined here ( $\mathrm{pH} 8)$, bare $n \mathrm{ZnO}$ is positively charged (Table 1 ), rendering deposition onto the negatively charged sand favorable. This favorable condition for particle retention dominates the NP transport behavior. As $n \mathrm{ZnO}$ deposits on the silica surface, the availability of favorable deposition sites decreases, and the likelihood of encountering another $n \mathrm{ZnO}$ particle bound to the collector surface increases. At 0.1 and $1 \mathrm{mM} \mathrm{NaNO}_{3}$, retained $n \mathrm{ZnO}$ particles appear to repel or "block" similarly-charged suspended NPs (Johnson and Elimelech 1995, Ryan and Elimelech 1996), giving rise to increasing particle elution with time. At other concentrations of the monovalent salt, the concentration of bare $n \mathrm{ZnO}$ at the column effluent decreases with time suggesting potential filter ripening. It is also interesting to note that as IS increases from 0.01 to $3 \mathrm{mM} \mathrm{NaNO}_{3}$, the breakthrough concentration of bare $n \mathrm{ZnO}$ particles increases as well. This trend is generally expected for particle deposition on an oppositely-charged collector surface (Elimelech et al. 1995). However, at the highest IS examined $\left(10 \mathrm{mM} \mathrm{NaNO}_{3}\right)$, the breakthrough concentration of $n \mathrm{ZnO}$ drops below that measured at $0.01 \mathrm{mM}$ (Fig. 6A). This uncharacteristic behavior can be attributed to physical straining of the large aggregates that form at this higher IS (Table 1). 

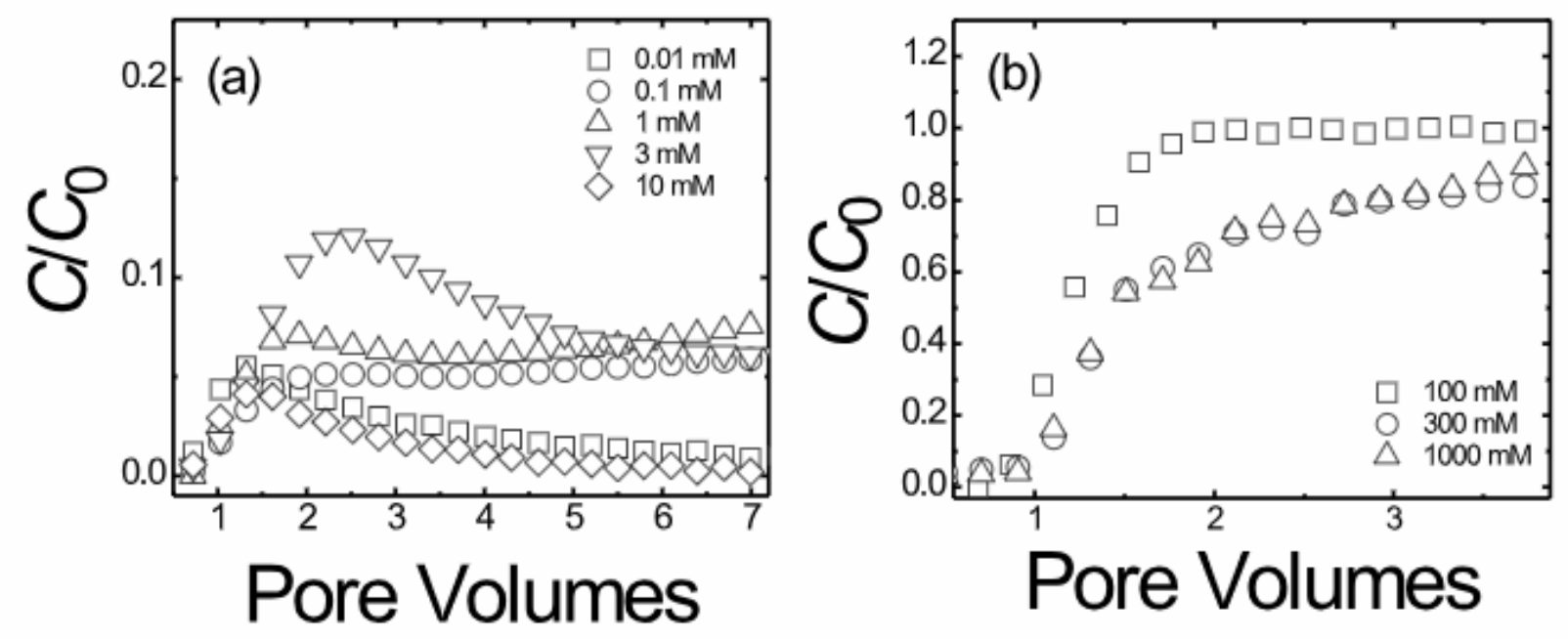

Figure 6. Measured breakthrough curves for (a) bare and (b) polymer-coated $n \mathrm{ZnO}$ particles suspended in $\mathrm{NaNO}_{3}$ at $\mathrm{pH} 8$.

Ben-Moshe et al. (Ben-Moshe et al. 2010) conducted deposition studies of bare $n \mathrm{ZnO}(<$ $100 \mathrm{~nm}$ nominal size, Aldrich) at 10 and $100 \mathrm{mM} \mathrm{NaCl}(\mathrm{pH} 7)$ in columns packed with glass beads. At both salt concentrations examined, significant particle retention (>98\%) was observed. At 10 $\mathrm{mM} \mathrm{NaCl}$, the average size of the $n \mathrm{ZnO}$ particles was measured by DLS to be approximately 1100 $\mathrm{nm}$, suggesting that very large aggregates were present in the NP suspensions (Ben-Moshe et al. 2010). In the present study, reproducible packed column experiments could not be conducted with 
bare $n \mathrm{ZnO}$ at salt concentrations above $10 \mathrm{mM}$ due to rapid and significant NP destabilization. In contrast, reproducible transport and characterization studies were carried out with polymer-coated $n \mathrm{ZnO}$ at $\mathrm{NaNO}_{3}$ concentrations as high as $1000 \mathrm{mM}$ (Table 1 and Fig. 6B). While bare $n \mathrm{ZnO}$ exhibits a positive surface charge at $\mathrm{pH} 8$, the polymer-coated NPs have a negative surface charge at this $\mathrm{pH}$ (Table 1), leading to a completely different deposition behavior. Whereas a large proportion of the bare $n \mathrm{ZnO}$ deposits onto the negatively charged sand grains, virtually all of the polymercoated $n \mathrm{ZnO}$ elute from the sand packed columns at $100 \mathrm{mM}$ IS and $-70 \%$ of the NPs elute when the IS is increased to $1 \mathrm{M} \mathrm{NaNO}_{3}$ (Fig. 6B). As noted above for the polymer-coated $n \mathrm{TiO}_{2}$ particles, this result can be attributed to electrosteric stabilization by the polymer coating on the Vive $\mathrm{Nano}^{\mathrm{TM}}$ particles (Elimelech et al. 1995, Franchi and O'Melia 2003). As mentioned previously, electrosteric stabilization results in decreased deposition onto the sand surface, as well as decreased NP aggregate formation, thus also reducing the likelihood of retention due to physical straining.

The measured breakthrough curves for the polymer-coated $n \mathrm{ZnO}$ particles suspended in the divalent salt are generally comparable to that of the polymer-coated $n \mathrm{TiO}_{2}$ particles (Fig. 5), with the exception of the experiment conducted at $3.3 \mathrm{mM} \mathrm{CaCl}_{2}$. It is interesting to note the dynamic deposition behavior of the polymer-coated $n \mathrm{ZnO}$ at this condition; the measured breakthrough curve consistently exhibits a rapid drop in the concentration of eluted particles with time. Careful inspection of Table 1 reveals that the size and PDI of the polymer-coated $n \mathrm{ZnO}$ increase significantly at $3.3 \mathrm{mM} \mathrm{CaCl}_{2}$. Hence, the favorable particle-particle interactions at this condition appear to promote filter ripening in the granular matrix. Overall, calculated attachment efficiencies for the negatively charged polymer-coated $n \mathrm{ZnO}$ particles increase over several orders of magnitude 
with increasing concentration of $\mathrm{NaNO}_{3}$ or $\mathrm{CaCl}_{2}$ (as noted with the polymer-coated $n \mathrm{TiO}_{2}$ ) (Table 1 and Fig. 4). In selected conditions as indicated above, dynamic nanoparticle deposition behavior is observed giving rise to nanoparticle elution profiles that rise or decrease with time. This behavior has previously been attributed to the mechanisms of straining, ripening, blocking, and aggregation (Elimelech et al. 1995, Liu et al. 1995, Solovitch et al. 2010) which are not considered within the classical theory of colloid filtration theory. Hence, in the discussion above, comparison of $\alpha$ values is included for purposes of qualitative interpretation of experimental observations.

\subsubsection{Environmental Implications}

Our findings provide insights into the manner in which bare and polymer-coated metal oxide NPs may behave upon release in water-saturated granular aqueous environments. Moreover, because the water flow rate and fine sand collectors employed here may be relevant to riverbank and slow sand filtration (Ray et al. 2003), the data obtained also provides insight into the capability of these water treatment techniques in removing bare and polymer-coated metal oxide NPs from water supplies. In practice, both these filtration techniques also possess organic layers (either at the filter surface or at the river/aquifer interface) - an aspect that is absent in the current study. The impact that such a biological layer can have on metal oxide NP removal is of interest and a subject of ongoing studies in our laboratory. Nonetheless, when river flow is high, the organic layer present at the river/aquifer interface may be lost, rendering a riverbank filtration system vulnerable to contaminant breakthrough (Ray et al. 2003). The current experiments best mimic such a high flow situation. 


\section{Conclusions}

This study demonstrates that in the absence of a polymer coating, $n \mathrm{TiO}_{2}$ and $n \mathrm{ZnO}$ particles aggregate rapidly, yielding polydisperse suspensions. While bare $n \mathrm{TiO}_{2}$ and $n \mathrm{ZnO}$ deposition onto sand surfaces is generally high, it can also be dynamic, with changes in elution behavior over time observed for selected conditions. Depending on the solution IS, bare $n \mathrm{ZnO}$ elution is observed to increase or decrease over time, suggesting that a complex interplay of mechanisms controls the deposition behavior of this NP. The suspension stability and transport behavior of the polymercoated NPs is quite different from their bare counterparts due to electrosteric stabilization. The polymer-coated NP suspensions are stable over a large range of $\mathrm{NaNO}_{3}$ concentrations with nearly all of the polymer-coated NPs eluting from the sand packed columns at IS below $300 \mathrm{mM}$. The surface modified particles are also more stable than the bare NPs in the presence of a divalent salt. Whereas transport experiments could not be conducted with bare NPs in solutions of $\mathrm{CaCl}_{2}$, the polyelectrolyte-coated NPs are moderately mobile at low concentrations of the divalent salt. Interestingly, both polymer-coated particles exhibit distinct elution behavior at $3.3 \mathrm{mM} \mathrm{CaCl}_{2}$ that is characteristic of ripening. Overall, this data suggests that upon release into the aquatic environment, bare $n \mathrm{ZnO}$ and $n \mathrm{TiO}_{2}$ may experience limited mobility due to aggregate formation. Moreover, such particles will likely be effectively removed by water filtration techniques such as slow sand and riverbank filtration. However, given that a majority of commercially and industrially employed NPs will be surface-functionalized, stabilized, or matrix-embedded, various derivatives of these basic metal oxide NP types may exhibit far greater mobility upon release and be more difficult to remove using contemporary water treatment approaches. 


\section{Acknowledgements}

This research was supported by NSERC, the Canada Research Chairs (CRC) Program and the Canada Foundation for Innovation (CFI). ARP is funded by both NSERC (Postgraduate Scholarship) and McGill University (McGill Engineering Doctoral Award). SJB and FR are partially supported by McGill Summer Undergraduate Research in Engineering (SURE) awards. The authors also thank Francis Duquette-Murphy and Kevin J. Wilkinson (University of Montreal) for NTA assistance, Julien Fatisson (McGill) for SEM assistance, Andrew Golsztajn and Ranjan Roy (McGill) for ICP-AES assistance, JeanPhilippe Masse (Centre de Caractérisation Microscopique des Matériaux, University of Montreal) for the TEM imaging and Che O'May (McGill) for assistance with manuscript editing. 


\section{References}

Adams, L.K., Lyon, D.Y., McIntosh, A. and Alvarez, P.J.J. (2006) Water Sci. Technol. 54, 327-334.

Aitken, R.J., Chaudhry, M.Q., Boxall, A.B.A. and Hull, M. (2006) Occup. Med-Oxford 56(5), 300-306.

Bai, W., Zhang, Z., Tian, W., He, X., Ma, Y., Zhao, Y. and Chai, Z. (2010) J. Nanopart. Res. 12(5), 16451654.

Ben-Moshe, T., Dror, I. and Berkowitz, B. (2010) Chemosphere 81(3), 387-393.

Bradford, S.A., Simunek, J., Bettahar, M., Van Genuchten, M.T. and Yates, S.R. (2003) Environ. Sci. Technol. 37(10), 2242-2250.

Bradford, S.A., Simunek, J., Bettahar, M., Van Genuchten, M.T. and Yates, S.R. (2006) Water Resour. Res. 42(12).

Bradford, S.A., Yates, S.R., Bettahar, M. and Simunek, J. (2002) Water Resour. Res. 38(12), 631-6312.

Carr, B., Malloy, A. and Warren, J. (2008) Innovat. Pharm. Technol. (26), 38-40.

Chowdhury, I., Hong, Y. and Walker, S.L. (2010) Colloids Surf., A 368(1-3), 91-95.

Choy, C.C., Wazne, M. and Meng, X. (2008) Chemosphere 71(9), 1794-1801.

Derjaguin, B.V. and Landau, L.D. (1941) Acta Phys. Chim. URSS 14, 633-662.

Dhawan, A., Taurozzi, J.S., Pandey, A.K., Shan, W., Miller, S.M., Hashsham, S.A. and Tarabara, V.V. (2006)

Environ. Sci. Technol. 40(23), 7394-7401.

Domingos, R.F., Baalousha, M.A., Ju-Nam, Y., Reid, M.M., Tufenkji, N., Lead, J.R., Leppard, G.G. and Wilkinson, K.J. (2009a) Environ. Sci. Technol. 43(19), 7277-7284.

Domingos, R.F., Tufenkji, N. and Wilkinson, K.J. (2009b) Environ. Sci. Technol. 43(5), 1282-1286.

Duan, Y., Liu, J., Ma, L., Li, N., Liu, H., Wang, J., Zheng, L., Liu, C., Wang, X., Zhao, X., Yan, J., Wang, S., Wang, H., Zhang, X. and Hong, F. (2010) Biomaterials 31(5), 894-899.

Dufour, E.K., Kumaravel, T., Nohynek, G.J., Kirkland, D. and Toutain, H. (2006) Mutat. Res-Gen. Tox. En. 607(2), 215-224.

Elimelech, M., Gregory, J., Jia, X. and Williams, R.A. (1995) Particle Deposition and Aggregation: Measurement, Modeling, and Simulation Butterworth-Heinemann, Oxford

Englert, B.C. (2007) J. Environ. Monitor. 9(11), 1154-1161.

Fang, X., Yu, R., Li, B., Somasundaran, P. and Chandran, K. (2010) J. Colloid Interf. Sci. 348(2), 329-334.

Fatisson, J., Domingos, R.F., Wilkinson, K.J. and Tufenkji, N. (2009) Langmuir 25(11), 6062-6069.

Federici, G., Shaw, B.J. and Handy, R.D. (2007) Aquat. Toxicol. 84(4), 415-430.

Finnegan, M.P., Zhang, H. and Banfield, J.F. (2007) J. Phys. Chem. C 111(5), 1962-1968.

Franchi, A. and O'Melia, C.R. (2003) Environ. Sci. Technol. 37(6), 1122-1129.

Franklin, N.M., Rogers, N.J., Apte, S.C., Batley, G.E., Gadd, G.E. and Casey, P.S. (2007) Environ. Sci. Technol. 41(24), 8484-8490.

Ge, Y., Schimel, J.P. and Holden, P.A. (2011) Environ. Sci. Technol. 45(4), 1659-1664.

Guzman, K.A.D., Finnegan, M.P. and Banfield, J.F. (2006) Environ. Sci. Technol. 40(24), 7688-7693.

Hao, L., Wang, Z. and Xing, B. (2009) J. Environ. Sci. 21(10), 1459-1466.

Hu, R., Gong, X., Duan, Y., Li, N., Che, Y., Cui, Y., Zhou, M., Liu, C., Wang, H. and Hong, F. (2010) Biomaterials 31(31), 8043-8050.

Huang, C.C., Aronstam, R.S., Chen, D.R. and Huang, Y.W. (2010) Toxicol. in Vitro 24(1), 45-55.

Jiang, X., Tong, M., Li, H. and Yang, K. (2010) J. Colloid Interf. Sci. 350(2), 427-434.

Johnson, P.R. and Elimelech, M. (1995) Langmuir 11(3), 801-812.

Joo, S.H., Al-Abed, S.R. and Luxton, T. (2009) Environ. Sci. Technol. 43(13), 4954-4959.

Kosmulski, M. (2002) Adv. Colloid Interface Sci. 99(3), 255-264.

Lecoanet, H.F., Bottero, J.Y. and Wiesner, M.R. (2004) Environ. Sci. Technol. 38(19), 5164-5169. 
Lecoanet, H.F. and Wiesner, M.R. (2004) Environ. Sci. Technol. 38(16), 4377-4382.

Lin, D. and Xing, B. (2008) Environ. Sci. Technol. 42(15), 5580-5585.

Litton, G.M. and Olson, T.M. (1993) Environ. Sci. Technol. 27(1), 185-193.

Liu, D., Johnson, P.R. and Elimelech, M. (1995) Environ. Sci. Technol. 29(12), 2963-2973.

Ma, L., Liu, J., Li, N., Wang, J., Duan, Y., Yan, J., Liu, H., Wang, H. and Hong, F. (2010) Biomaterials 31(1), 99-105.

Mattigod, S.V., Fryxell, G.E., Alford, K., Gilmore, T., Parker, K., Serne, J. and Engelhard, M. (2005) Environ. Sci. Technol. 39(18), 7306-7310.

Maynard, A.D., Aitken, R.J., Butz, T., Colvin, V., Donaldson, K., Oberdörster, G., Philbert, M.A., Ryan, J., Seaton, A., Stone, V., Tinkle, S.S., Tran, L., Walker, N.J. and Warheit, D.B. (2006) Nature 444(7117), 267269.

Moos, P.J., Chung, K., Woessner, D., Honeggar, M., Cutler, N.S. and Veranth, J.M. (2010) Chem. Res. Toxicol. 23(4), 733-739.

Mortimer, M., Kasemets, K. and Kahru, A. (2010) Toxicology 269(2-3), 182-189.

Mueller, N.C. and Nowack, B. (2008) Environ. Sci. Technol. 42(12), 4447-4453.

Nowack, B. and Bucheli, T.D. (2007) Environ. Pollut. 150(1), 5-22.

Pelley, A.J., Tufenkji, N. (2008) J. Colloid Interface Sci. 321(1), 74-83.

Pena, M.E., Korfiatis, G.P., Patel, M., Lippincott, L. and Meng, X. (2005) Water Res. 39(11), 2327-2337.

Petosa, A.R., Jaisi, D.P., Quevedo, I.R., Elimelech, M. and Tufenkji, N. (2010) Environ. Sci. Technol. 44(17), 6532-6549.

Pettibone, J.M., Cwiertny, D.M., Scherer, M. and Grassian, V.H. (2008) Langmuir 24(13), 6659-6667.

Ray, C., Melin, G. and Linsky, R.B. (2003) Riverbank Filtration: Improving Source-Water Quality, Kluwer Academic Publishers, Dordrecht, NL.

Reddy, K.M., Feris, K., Bell, J., Wingett, D.G., Hanley, C. and Punnoose, A. (2007) Appl. Phys. Lett. 90(21). Robichaud, C.O., Tanzil, D., Weilenmann, U. and Weisner, M.R. (2005) Environ. Sci. Technol. 39(22), 8985-8994.

Roh, J.Y., Park, Y.K., Park, K. and Choi, J. (2010) Environ. Toxicol. Phar. 29(2), 167-172.

Ryan, J.N. and Elimelech, M. (1996) Colloids Surf., A 107, 1-56.

Sayes, C.M., Wahi, R., Kurian, P.A., Liu, Y., West, J.L., Ausman, K.D., Warheit, D.B. and Colvin, V.L. (2006) Toxicol. Sci. 92(1), 174-185.

Schanen, B.C., Karakoti, A.S., Seal, S., Drake III, D.R., Warren, W.L. and Self, W.T. (2009) ACS Nano 3(9), 2523-2532.

Sharma, V., Shukla, R.K., Saxena, N., Parmar, D., Das, M. and Dhawan, A. (2009) Toxicol. Lett. 185(3), 211 218.

Sinha, R., Karan, R., Sinha, A. and Khare, S.K. (2011) Bioresource Technol. 102(2), 1516-1520.

Solovitch, N., Labille, J., Rose, J., Chaurand, P., Borschneck, D., Wiesner, M.R. and Bottero, J.Y. (2010) Environ. Sci. Technol. 44(13), 4897-4902.

Suzuki, H., Toyooka, T. and Ibuki, Y. (2007) Environ. Sci. Technol. 41(8), 3018-3024.

Tseng, W.J. and Lin, K.C. (2003) Mat. Sci. Eng. A 355(1-2), 186-192.

Tufenkji, N. and Elimelech, M. (2004a) Environ. Sci. Technol. 38(2), 529-536.

Tufenkji, N. and Elimelech, M. (2004b) Langmuir 20(25), 10818-10828.

Tufenkji, N. and Elimelech, M. (2005) Langmuir 21(3), 841-852.

Tufenkji, N., Miller, G.F., Ryan, J.N., Harvey, R.W. and Elimelech, M. (2004) Environ. Sci. Technol. 38(22), 5932-5938.

Valant, J., Drobne, D., Sepčić, K., Jemec, A., Kogej, K. and Kostanjšek, R. (2009) J. Hazard. Mater. 171(1-3), 160-165. 
Verwey, E.J.W. and Overbeek, J.T.G. (1948) Theory of the Stability of Lyophobic Colloids, Elsevier, Amsterdam.

Wang, Z.L. (2004) J. Phys. Condens. Matter 16(25), R829-R858.

Warheit, D.B., Webb, T.R., Reed, K.L., Frerichs, S. and Sayes, C.M. (2007) Toxicology 230(1), 90-104.

Wiesner, M.R. and Bottero, J.-Y. (2007) Environmental Nanotechnology, The McGraw-Hill Companies, New York.

Yao, K.M., Habibian, M.T. and O'Melia, C.R. (1971) Environ. Sci. Technol. 5(11), 1105-1112.

Zhang, Y., Chen, Y., Westerhoff, P. and Crittenden, J. (2009) Water Res. 43(17), 4249-4257.

Zhou, D. and Keller, A.A. (2010) Water Res. 44(9), 2948-2956.

Zhou, J., Xu, N. and Wang, Z.L. (2006) Adv. Mater. 18(18), 2432-2435. 